\title{
A Review of the Audio-Vestibular Criteria Used to Request MRI Imaging for Vestibular Schwannoma Detection in a District General Hospital
}

\author{
Saeed HS, Yao A, Kaushik V. Stepping Hill Hospital England
}

\section{Background:}

Currently there is no national consensus as to which audiovestibular symptoms warrant MRI imaging to exclude vestibular schwannoma (VS).

\section{Objectives:}

Assess audio-vestibular indicators used in our department to arrange MRI internal auditory meati (IAM).

Form a local protocol for MRI IAM imaging based on our analysis and concordance with published guidelines.

\section{Methods:}

Retrospective review of 101 MRI IAM scan clinical indications (Feb 2017 to June 2017). Concordance of audio-vestibular indications with current Nashville, Charing Cross, Oxford and Northern guidelines was assessed.

(see table 1).

\section{Results:}

2 VS diagnosed; one VS missed if Charing Cross and Northern criteria used alone. $16 \%$ of scans did not meet any guideline audio-vestibular criteria (see fig 1). Highest compliance was with Nashville guidelines (83\%)

(see fig 2).

\section{Conclusions:}

Adopting one guideline risks missing VS diagnosis. We have highlighted a large variability between clinicians in regards to when MRI IAMs should be requested. We therefore recommend ENT departments audit their practice and set a local imaging protocol, minimising unnecessary expenditure and the risk of missing a VS. We are currently reviewing positive VS scans in order to establish a local protocol.

Guideline
Oxford Guideline ${ }^{[8]} .15 \mathrm{~dB}$ asymmetry between
mean thresholds of tested frequencies+Unilateral
tinnitus with normal hearing.
Northern Guideline ${ }^{[9]} .20 \mathrm{~dB}$ asymmetry between
two contiguous frequencies+Unilateral tinnitus.
Charing Cross Protocol ${ }^{[10]} .20 \mathrm{~dB}$ asymmetry
between two contiguous frequencies or $15 \mathrm{~dB}$ if
normal hearing in one ear.
Nashville Otology Group ${ }^{[11]} .15 \mathrm{~dB}$ asymmetry
at one frequency $0.5-4 \mathrm{kHz}+$ Unilateral tinnitus.
dB: decibel

Table 1: Current major guidelines highlighting suggested audio-vestibular indications for MRI IAM. We assessed our compliance with the above guidelines when requesting scans ${ }^{1}$

\section{Percentage Total Compliance with Protocols}

$100 \%$

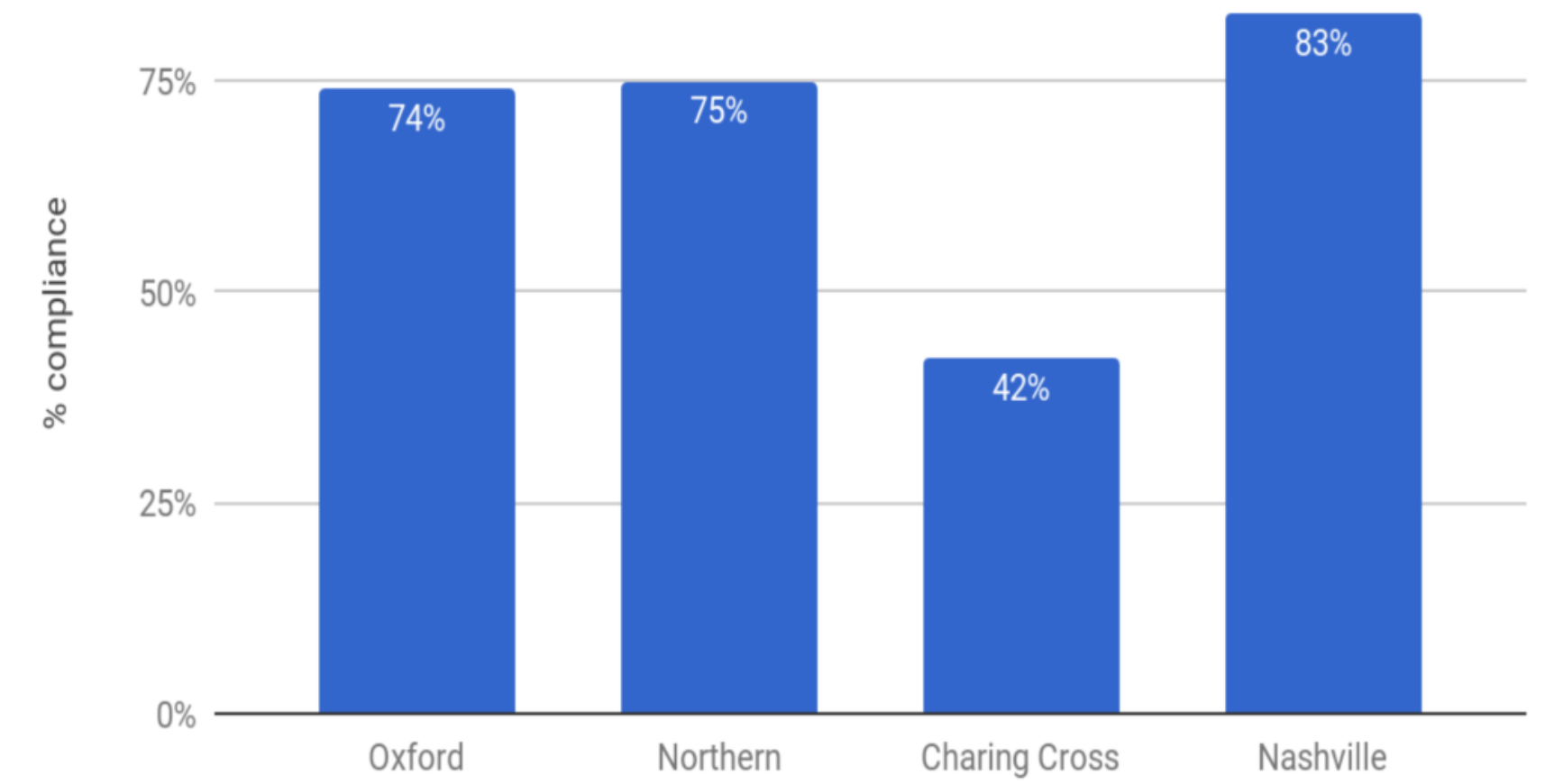

Fig 1: Indications for MRI IAM request. 1\% equates to 1 patient.

1. Nash R, Majithia A, Singh A. The Agreement between Protocols for the Investigation of Asymmetrical Audiovestibular Symptoms. J Int Adv Otol. 2016
Fig 2: Our department's scan indication compliance with the current guidelines in table 1 . We were least compliant with the Charing cross guideline and most with the Nashville Guideline. 